$\mathrm{AB} 0377$

ARE CO-MORBIDITIES DURING RHEUMATOID ARTHRITIS DIFFERENT FROM THOSE IN ANKYLOSING SPONDYLOARTHRITIS ?

M.A. El Achek, on behalf of Jguirim.M, Farhat.A, Braham.M, Bejia.I, Touzi.M, Zrour S, Bergaoui.N. Rheumatology, Fattouma Bourguiba Hospital, Monastir, Tunisia

Background: Patients with inflammatory rheumatic diseases are certainly not unscathed from a lot of comorbidities which may be due to the systemic inflammatory activity of rheumatic diseases themselves, immune dysfunction, or iatrogenic, they may also occur independently.

Cardiovascular morbidity remains one of the most important to detect and is increased during these diseases.

So are there significant differences between co-morbidities associated with rheumatoid arthritis (RA) and those with ankylosing spondyloarthritis (AS)?

Objectives: To highlight the difference between comorbidities in RA and AS.

Methods: This is a retrospective study of 111 patients followed for RA ACR 1987 criteria), and 60 patients followed for AS, compiled between January 2005 and December 2016.

Results: The mean age of patients with RA was 51.04 years [ $18-80$ years] with a sex ratio $(M / F)$ of 0.18 . The average duration of disease progression was 6.54 years [0-29 years]. The mean age of patients with AS was 40.4 years [18-61] with a sex ratio $(\mathrm{M} / \mathrm{F})$ of 19 . The average duration of disease progression was 16.8 years [ $1-45$ years].

About cardiovascular comorbidities, $16.2 \%$ of patients with RA and $5.1 \%$ with AS were diagnosed with high blood pressure. Dyslipidemia was found in $2.7 \%$ of patients with RA and in $0 \%$ with AS.

$31.5 \%$ with RA and $21.7 \%$ of AS have overweight and obesity was illustrated in $22.5 \%$ of $R A$ and $11.7 \%$ of AS.

Heart and coronary failure were documented in $5.4 \%$ of RA and $1.7 \%$ of AS. Likewise renal failure in $3,6 \%$ of RA and $3.4 \%$ of AS. Diabetes was found in $18 \%$ of RA and $10 \%$ of AS. Hypothyroidism in $5.4 \%$ of RA and $1.7 \%$ of AS. Gout attack in $0.9 \%$ of RA and $0 \%$ with AS and osteoporosis in $21.3 \%$ of RA and $40 \%$ of AS.

Conclusions: Our study concluded at the frequency of comorbidities and mostly cardiovascular in rheumatoid arthritis compared with AS. Osteoporosis is also more common in our studied population with RA, although not rare with our patients with AS. This can be explained by the prescription of corticosteroid therapy in RA.

Disclosure of Interest: None declared

DOI: 10.1136/annrheumdis-2018-eular.5788

\section{AB0378 PULMONARY AFFECTION IN EGYPTIAN PATIENTS WITH RHEUMATOID ARTHRITIS}

M.S. Abdel-Baky ${ }^{1}$, D.F. Mohamed ${ }^{1}$, S.H. Hamza ${ }^{1}$, D.A. El Sherbiny ${ }^{1}$, M. Rezk ${ }^{1}$, A. A. Gomaa ${ }^{2} .{ }^{1}$ Department of Medicine Division of Rheumatology; ${ }^{2}$ Department of Chest diseases, Ain Shams University, Cairo, Egypt

Background: Rheumatoid arthritis $(\mathrm{RA})$ is a disabling autoimmune systemic inflammatory disease. It manifests as peripheral symmetric inflammatory polyarthritis and produces a wide range of extra-articular manifestations. Interstitial lung disease (ILD), a diffuse progressive disease of the lung parenchyma, is the most serious manifestation of RA lung affection, it remains as a significant source of morbidity and mortality.

Objectives: To evaluate the frequency and pattern of pulmonary affection in a cohort of Egyptian rheumatoid arthritis (RA) patients and the relation to disease activity and severity.

Methods: Seventy RA patients who fulfilled 2010 (ACR/EULAR) classification criteria underwent full clinical assessment, plain $X$ ray chest, chest high-resolution computed tomography (HRCT) with assessment of the extent and severity of pulmonary affection by Warrick score. Pulmonary function tests (PFTs) including diffusion lung capacity for carbon monoxide (DLCO) were done. Transthoracic echocardiography to screen for pulmonary hypertension $(\mathrm{PH})$. Assessment of disease activity by DAS28 score and of radiographic joint damage by modified Larsen score.

Results: The mean age of the patients was $44 \pm 10.8$ years;females $(87.1 \%)$ and males $(12.9 \%)$, mean disease duration $7.3 \pm 6$ years. PFTs were abnormal in $(45.7 \%)$ with restrictive pattern in $(24.3 \%)$ of patients followed by small airway affection in (10\%), mixed pattern in $(8.6 \%)$, the least is the obstructive pattern in $(2.8 \%)$ of patients. DLCO was abnormal in $(72.86 \%)$ with mild affection in $(48.57 \%)$, moderate in $(15.7 \%)$ and severe affection in $(8.6 \%)$ of patients. HRCT abnormalities were found in 30 patients $(42.85 \%)$. Interstitial abnormalities were detected in (35.7\%). Septal or reticular lines, ground glass appearance, pleural irregularities and bronchiectasis were the most common findings. Most common HRCT pattern was nonspecific interstitial pneumonia (NSIP) in 12.8\% (9/70), usual interstitial pneumonia (UIP) in $7 \%(5 / 70)$, organising pneumonia (OP) in $1.4 \%(1 / 70)$ and indeterminate subtype in 14\% (10/70). HRCT total score (Warrick score) was correlated with age, disease activity (DAS ESR 28), ESR, modified Larsen score, FVC, FEV1 and DLCO. Age, dyspnea and DLCO impairment were significant predictors for development of HRCT chest abnormalities. Pulmonary hypertension(sPAP $>30 \mathrm{mmHg}$ ) was detected in (14\%) of patients.

Conclusions: Pulmonary abnormalities are common in Egyptian RA patients HRCT and PFTs including DLCO can be used effectively for early diagnosis and monitoring of pulmonary affection in RA patients. DLCO can detect pulmonary abnormalities early in clinically asymptomatic patients. Age, disease activity and severity, PFTs and ESR are correlated with the pulmonary affection in RA. Age dyspnea and DLCO impairment are significant predictors of pulmonary affection in RA patients. Echocardiography can be used as a screening tool for detection of pulmonary hypertension.

Disclosure of Interest: None declared

DOI: 10.1136/annrheumdis-2018-eular.3235

\section{AB0379 MUSCULOSKELETAL INVOLVEMENTS IN GIANT CELL ARTERITIS}

M. Tougorti, T. Ben Salem, M.S. Hamdi, M. Lamloum, I. Ben Ghorbel, M.

$\mathrm{H}$. Houman. Internal medecine, RABTA HOSPITAL, Tunis, Tunisia

Background: Joint involvement is frequent in Giant cell arteritis (GCA), mostly polymyalgia rheumatica (PMR). The aim of this study was to describe clinical features of joint involvement in GCA.

Objectives: To compare patients according to the presence or not of PMR.

Methods: A retrospective and descriptive study of 96 patients with GCA diagnosed between 2000 and 2015. ACR 1990 criteria were used for the diagnosis of GCA. Clinical, biological and histological features were recorded and analysed.

Results: Joint involvements were noted in 67 patients with GCA (69.8\%); 34 women and 33 men. Mean age at diagnosis was $72.4 \pm 6.36$ years. PMR was diagnosed in 45 patients (46.8\%) and revealed the disease in two patients. Neck pain was noted in 48 patients. Twenty one patients (21.8\%) complained of peripheral arthralgias which revealed GCA in five cases. Joint manifestations were associated to cardinal symptoms of GCA: headache (97\%), jaw claudication $(62 \%)$, scalp tenderness (49.3\%) and ophthalmologic manifestations (36.9\%). Erythrocyte sediment rate and C-reactive protein were high in $89.2 \%$ and $82.7 \%$ of cases respectively.

Constitutional symptoms ( $60 \%$ vs $39.2 \%$; $p=0.042$ ), jaw claudication $(68.2 \%$ vs $47.1 \% ; \mathrm{p}=0.038)$ and neck pain $(62.2 \%$ vs $39.2 \% ; \mathrm{p}=0.024)$ were significantly more frequent in patients with PMR. Peripheral arthralgias (28.9\% vs $15.7 \%$ ) were more frequent in patients with PMR without significant differences. Giant cell vasculitis on temporal arterial biopsy was more frequent in patients with PMR $(57 \%$ vs $30 \% ; p=0.037)$.

Corticosteroids were given in $97 \%$ of patients while methotrexate was used in $20.9 \%$.

Conclusions: PMR in patients with GCA seem to be associated to different joint manifestations.

Disclosure of Interest: None declared

DOI: 10.1136/annrheumdis-2018-eular.3798

\section{AB0380 DELAY IN TIME TO DIAGNOSIS INCREASES THE RISK OF SUFFERING CLASSIC CARDIOVASCULAR RISK FACTORS IN PATIENTS WITH RHEUMATOID ARTHRITIS}

M. Robustillo Villarino ${ }^{1}$, A. Sendra García ${ }^{2}$, J.J. Alegre Sancho ${ }^{1} .{ }^{1}$ Rheumatology, Hospital Universitari Dr Peset i Aleixandre; ${ }^{2}$ Rheumatology, Foundation for the Promotion of Health and Biomedical Research of Valencia (FISABIO), Valencia, Spain

Background: Rheumatoid arthritis (RA) is a chronic inflammatory disease that constitutes an independent cardiovascular risk factor (CVRF). In addition, patients with RA have a higher prevalence of CVRF than the general population.

Objectives: To assess whether delay in time to diagnosis of the disease may increase the risk of CVRF in patients with RA.

Methods: Patients diagnosed with RA, according to the EULAR/ACR 2010 clas sification criteria, were consecutively selected and recruited for a period of 12 months. Delay in time to diagnosis was calculated as the interval between the beginning of first joint symptoms and the diagnosis of RA with start of specific treatment. Furthermore, the presence or absence of arterial hypertension (AHT), dyslipidemia (DL) and diabetes mellitus (DM) were recorded. Whether its diagnosis was prior or subsequent to the diagnosis of the inflammatory disease was also recorded. SPSS version 17.0 software was used for statistical analysis, considering statistical significance for $\mathrm{p}<0.05$.

Results: A total of 244 patients were studied, $73.8 \%$ (180) of whom were women and $26.2 \%$ (64) men. The mean age was 60.42 years (SD 13.24). Mean Delay in time to diagnosis was 2.1 years (SD 5.5). Mean age at diagnosis was 48.9 years (SD 15.7). Regarding classic CVRF, the percentage of patients with AHT, DL and DM before RA diagnosis were $17.6 \%(43), 6.1 \%(15)$ and $6.1 \%(15)$, respectively. 
After RA diagnosis, 22.5\% (55), 43.4\% (106) and 3.3\% (8) of patients were diag nosed with AHT, DL and DM. Delay in time to diagnosis was significantly associated with $\mathrm{AHT}, \mathrm{DL}$ and DM diagnosis after RA diagnosis.

Conclusions: A higher inflammatory load, such as that accumulated in RA patients who have delayed the start of treatment, is associated with a higher probability of developing CVRF, which are associated with the appearance of vascular structural damage in the long term. These results are consistent with the effect of inflammatory cytokines on peripheral tissues (increased lipolysis in adipose tissue, increased insulin resistance, increased arterial stiffness).

\section{REFERENCES:}

[1] Boyer JF, Gourraud PA, Cantagrel A, Davignon JL, Constantin A. Traditional cardiovascular risk factors in rheumatoid arthritis: A meta-analysis. Joint Bone Spine 2011 Mar;78:179-83.

[2] Dessein PH, Joffe BI, Veller MG, Stevens BA, Tobias M, Reddi K, et al. Traditional and nontraditional cardiovascular risk factors are associated with atherosclerosis in rheumatoid arthritis. J Rheumatol 2005 Mar;32:43542.

[3] Symmons DPM, Gabriel SE. Epidemiology of CVD in rheumatic disease, with a focus on RA and SLE. Nat Rev Rheumatol 2011;7:399-408.

Disclosure of Interest: None declared

DOI: 10.1136/annrheumdis-2018-eular.6506

\section{AB0381 CLINICAL AND RADIOGRAPHIC CHARACTERISTICS OF AIRWAY DISEASE IN PATIENTS WITH RHEUMATOID ARTHRITIS}

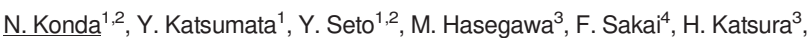
H. Yamanaka ${ }^{1} .{ }^{1}$ Institute of Rheumatology, Tokyo Women's Medical University, Tokyo; ${ }^{2}$ Division of Rheumatology; ${ }^{3}$ Division of Respiratory Medicine, Tokyo Women's Medical University Yachiyo Medical Center, Chiba; ${ }^{4}$ Department of Diagnostic Radiology, Saitama International Medical Center, Saitama Medical University, Saitama, Japan

Background: Airway disease (AD) has drawn attention both clinically and etiologically in rheumatoid arthritis (RA), but is still poorly understood.

Objectives: We aimed to elucidate the clinical and radiographic characteristics of $A D$ in patients with $R A$.

Methods: We retrospectively reviewed high-resolution computed tomography (HRCT) images and clinical data of 131 consecutive RA patients in whom HRCT were scanned for clinical purposes and screening. Overlap patients with other collagen tissue diseases and patients complicated with active infection or lung cancer were excluded. Patients who had a history of drug-induced lung disease, thoracic radiation, or exposure to dust were also excluded. HRCT images were reviewed independently by a pulmonologist and a radiologist in blind fashions, and cases of disagreement were discussed to reach a final consensus. AD was radiographically sub-categorised into 3 sub-groups: central $A D$, small $A D$, and middle lobe and lingular bronchiectasis. The associations between $A D$ and interstitial lung disease (ILD) and each pair of the subtypes of AD were analysed by Fisher's exact test. The risk factors for AD and subtypes of $A D$ were identified by multivariate logistic regression analyses.

Results: The mean age of the patients was 65 years old, the mean disease duration of the patients was 123 months, $69 \%$ of the patients were women, and $42 \%$ of the patients had past/current histories of smoking. The mean Disease Activity Score 28 (DAS28)-erythrocyte sedimentation rate (ESR) value was 2.87. AD and ILD were observed in $53(40 \%)$ and $36(27 \%)$ patients, respectively, and both in $19(15 \%)$ patients. AD and ILD were not significantly associated $(p=0.11)$. By multivariate logistic regression analyses, rheumatoid factor (RF) was identified as risk factors for whole $\mathrm{AD}$ (odds ratio [OR] 2.7; 95\% confidence interval [CI], 1.0 to 6.9; $p=0.04)$. Central $A D$, small $A D$, and middle lobe and lingular bronchiectasis were observed in $45(34 \%), 31(24 \%)$, and $17(13 \%)$ patients, respectively. Each pair of these 3 subtypes were significantly associated with each other $(p<0.001$ in all comparisons). By multivariate logistic regression analyses without considering the overlaps with multiple subtypes of $A D$ in the same patients, age and RF were identified as risk factors for central AD: the OR for age was $1.04(95 \% \mathrm{Cl}, 1.00$ to 1.08; $p=0.04)$; the OR for RF was $3.0(95 \% \mathrm{Cl}, 1.1$ to $8.5 ; \mathrm{p}=0.034)$. In contrast, DAS28-ESR values was identified as a risk factor for small AD: the OR for DAS28-ESR values was $1.5(95 \% \mathrm{Cl}, 1.0$ to $2.4 ; \mathrm{p}=0.0498)$. Lastly, no significant risk factor was identified for middle lobe and lingular bronchiectasis by the multivariate logistic regression analysis, although disease duration tended to be longer in the patients with middle lobe and lingular bronchiectasis than in those without $(p=0.12)$. In contrast, smoking histories was not significantly associated with whole AD or any subtypes of AD.

Conclusions: Radiologically defined $A D$ was frequent comorbidity in RA patients, and multiple subtypes of AD were observed and coexisted. Furthermore, $A D$ may be related to the pathology of $R A$, and different $A D$ subtypes may have distinct risk factors. Prospective studies with early RA patients were warranted to further clarify these findings and clinical impact of $A D$.

Disclosure of Interest: None declared

DOI: 10.1136/annrheumdis-2018-eular.3833

\section{AB0382 RAPAMYCIN SELECTIVELY INCREASES CIRCULATING TREGCELLSAND MAINTAIN REMISSION OF PATIENTS WITH RHEUMATOID ARTHRITIS}

N. Yan ${ }^{1}$, H. Yao ${ }^{1}$, F. Hu ${ }^{1}$, J. Liang ${ }^{1}$, H. Niu ${ }^{1}$, X. Li ${ }^{1}$, C. Gao ${ }^{2}$, C. Wang ${ }^{1} .{ }^{1}$ he Second Hospital of Shanxi Medical University, Taiyuan, China; ${ }^{2}$ Brigham and Women's Hospital, Boston, USA

Background: It is thought that Rheumatoid arthritis (RA) arises from a breakdown in immunological self-tolerance. We have givena direct evidence for this conceptionthat absolute number of peripheral $\mathrm{CD} 4^{+}$Regulatory T-cells (Tregs) decreased inRA patients ${ }^{[1]}$. Furthermore, rapamycin can significantly induce immune tolerance through up-regulate Tregs and down-regulate Th17 cells ${ }^{[2]}$

Objectives: To investigate the effect of rapamycin on the absolute numbers of Th17 and Treg cells and on maintenance of disease remission in RA patients instead of DMARDs.

Methods: Thirty-two patients, who achieved remission(DAS28 $\leq 2.6$ ) by the treatment with two kinds of DMARDs for more than half a year, received rapamycin at a dose of $0.5 \mathrm{mg}$ every other dayfor 12 weeks. Before and after treatment with rapamycin, thediseaseactivity and immunological assessments of them were performed. In this study, BD Trucount tubes with the lyophilized pellet of a known number of internal counting beads were used for determining absolute counts of total $\mathrm{CD} 4^{+} \mathrm{T}$ cells in peripheral blood and then calculating the absolute number of Th17 cells and CD4 ${ }^{+}$Tregs.

Results: At week $12,65.6 \%$ of the patients maintained remission (DAS28 $\leq 2.6$ ). TheDAS28 was increased from a median of 2.03(at week 0 ) to 2.15 (at week 12 ) $(p>0.05)$. The absolute numberof Treg cells was increased significantly from a median of 22.16 (at week 0 ) to 32.19(at week 12) ( $P=0.039$ ). The absolute number of Th17 cells was decreased from a median of5.98(at week 0) to 5.56(at week 12 ( $p>0.05$ ). The ratio of Th17/Treg cells was also decreased from a median of 0.245 (at week 0) to 0.19 (at week 12) ( $p>0.05)$. At the same time, the mean dosage of prednisone decreased from $6.29 \mathrm{mg} / \mathrm{d}$ to $5.35 \mathrm{mg} / \mathrm{d}$ and thatof DMARDs were also reduced from $93.75 \%$ to $56.25 \%$.

Conclusions: Rapamycin was effective in the maintenance of remission(DAS28 $\leq 2.6$ )by increase of Treg cells and correcting the imbalance of Th17/Treg cells. Meantime, the mean dosage of conventional drugs such as glucocorticoid and DMARDs gradually decreased. In the future, rapamycin may replace current immunosuppressant for treatment of RA

\section{REFERENCES}

[1] Niu H, Li Z, He J, et al. Rapamycin selectively increases circulating Treg cells and modulates the imbalance of Th17/Treg cells in patients with low active rheumatoid arthritis.

[2] Yang X, Yao Q, Hu X, et al. Rapamycin-conditioned dendritic cells induced immune tolerance through the regulation of Treg/Th17 cells in mice. Zhonghua Yi Xue Za Zhi 2015 Aug 11;95(30):2469-73.

Disclosure of Interest: None declared

DOI: 10.1136/annrheumdis-2018-eular.2564

\section{AB0383 CHANGES OF METABOLIC BIOMARKER LEVELS UPON ANTI-TNF THERAPY IN RHEUMATOID ARTHRITIS PATIENTS}

N. Bodnár ${ }^{1}$, A. Pusztai ${ }^{1}$, E. Végh ${ }^{1}$, Á. Horváth ${ }^{1}$, S. Szántó ${ }^{1}$, G. Szücs ${ }^{1}$, A. Hamar ${ }^{1}$ A. Domján ${ }^{1}$, K. Hodosi ${ }^{1}$, I. Seres ${ }^{2}$, G. Kerekes ${ }^{3}$, Z. Szekanecz ${ }^{1} .{ }^{1}$ Department of Rheumatology; ${ }^{2}$ Department of Internal Medicine; ${ }^{3}$ Intensive Care Unit, Department of Internal Medicine, University of Debrecen, Faculty of Medicine, Debrecen, Hungary

Background: Rheumatoid arthritis (RA) has been associated with cardiovascula disease and metabolic syndrome. Numerous pro-inflammatory cytokines (e.g TNF- $\alpha$, IL-1, IL-6) are released, which cytokines cause increased reactive oxygen species (ROS) production and thereby contribute to the increased lipid peroxidation and reduction of many antioxidants. These processes not only lead to the deterioration of joints and other tissues but may also contribute to comorbidities, such as atherosclerosis.

Objectives: The aim of this study was to assess the effects of anti-TNF therapy on different metabolic markers, such as PON1 (paraoxonase 1), arylesterase chemerin and adiponectin. We also investigated whether these biomarkers correlated with various demographic, clinical and laboratory markers. 